\title{
Special issue on AMEF 2016: Introduction
}

\author{
Theodore Panagiotidis* \\ University of Macedonia, Department of Economics, Greece
}

Received: 12 December 2016

Accepted: 12 December 2016

This special issue of the Economics and Business Letters was the result of the 2nd AMEF (Applied Macroeconomics and Empirical Finance) that took place in the Department of Economics, University of Macedonia, Thessaloniki, Greece on the 6th and the 7th of May 2016. This event gave the opportunity to both experienced and young researchers, post-docs and $\mathrm{PhD}$ students to present their work and get feedback. The keynote speeches were delivered by Prof Karim Abadir from Imperial College, UK, Prof Thanasis Stengos from the University of Guelph, Canada and Prof Anastasios Xepapadeas from the Athens University of Economics and Business, Greece.

The first contribution to the special issue is from Cuestas. This paper examines the controversy surrounding the unexpected oil price fall that took place in 2013-2015. The author examines whether the GDP-unemployment relationship in Spain was affected by the turbulence in the oil market. The author distinguishes between the unemployment rate and the equilibrium unemployment rate by using the Hodrick-Prescott filter. The nonlinear autoregressive distributed lag (NARDL) model is employed since it can accommodate both $\mathrm{I}(0)$ and $\mathrm{I}(1)$ variables. The results reveal that supply shocks do not seem to have an effect on the unemployment rate of Spain; they do have on the equilibrium rate. A rising oil price is affecting the equilibrium rate of the Spanish unemployment more than the equivalent fall.

The second contribution, by Asteriou and Sarantidis, examines the relationship between political instability and stock market returns. The authors employ data from 18 OECD countries for banking stock returns, general indices returns and combine information from 27 alternative political instability indicators. Explanatory factor analysis and principal components are used to reduce the large number of variables that refer to political uncertainty. GARCH in mean models are used to gauge the effect of uncertainly on both the returns and the variance. The basic message of the analysis confirms the negative relationship between political instability and bank/ stock market returns. Additionally, it was found that some political instability indicators do not affect returns and some might affect them in a positive way. Overall the

\footnotetext{
*E-mail: tpanag@uom.gr.

Citation: Panagiotidis, T. (2016) Special Issue on AMEF 2016: Introduction, Economics and Business Letters, 5(4), 105-106.
} 
relationship between instability and returns is not straightforward and additional work is required.

The third contribution by Papadamou et al. looks into the effect of central bank transparency and output volatility. This letter is employing data from 36 countries for the period 1998 to 2005. The panel methodological framework accounts for the presence of heteroscedasticity. The results reveal the negative relationship between central bank transparency and both inflation and output variability. The authors conclude that more transparency is associated with less volatility.

Last but not least is the contribution by Rafailidis and Katarkilidis. They look into the long run relationship between the effective rate of the US dollar and oil prices. The sample under investigation covers the period from January 1986 to August 2014. The potential asymmetry of the relationship is taken into account. The authors employ the hidden cointegration approach. The possibility of structural breaks is also examined. This analysis reveals the asymmetric long run relationship between the two markets.

On behalf of the scientific committee, I would like to thank the Economics and Business Letters for covering the conference with a special issue and the University of Macedonia for hosting the event. We would also like to thank the organizing committee, the scientific committee, the presents and the referee of the special issue. 